\title{
Acute perforated duodenal ulcer is not associated with Helicobacter pylori infection
}

\author{
D H Reinbach, G Cruickshank, K E L McColl
}

\begin{abstract}
Most patients with chronic duodenal ulcer disease have Helicobacter pylori infection and eradicating it considerably reduces the relapse rate. The prevalence of $H$ pylori in 80 patients (mean age $=52$ years, range 17-85) presenting with acute perforated duodenal ulcer was examined and compared with age and sex matched hospital control patients. $H$ pylori state was assessed by serum anti- $H$ pylori IgG (Helico-G kit, Porton) using a titre of 18 or less as negative with a specificity of $89 \%$ and sensitivity of $88 \%$. Only $47 \%$ of the perforated duodenal ulcer patients were positive for $H$ pylori and this was similar to the value of $\mathbf{5 0 \%}$ in the controls. In $\mathbf{5 1}$ of the perforated duodenal ulcer patients ${ }^{14} \mathrm{C}$-urea breath tests were also performed 4-10 weeks after surgery and this confirmed that only $49 \%$ were positive for $H$ pylori. None of these patients had received perioperative drugs that might have eradicated the infection. The $\boldsymbol{H}$ pylori positive and $H$ pylori negative perforated duodenal ulcer patients were similar with respect to age $(53,51)$, smoking $(84 \%, 83 \%)$, and consumption of more than 15 units of alcohol per week $(42 \%, 38 \%)$. Duodenal ulcer disease had been diagnosed before acute perforation in only $24 \%$ of those with $H$ pylori and also $24 \%$ of those without the infection. Regular non-steroidal anti-inflammatory drug (NSAID) use was common in both those with (44\%) and without $(45 \%) H$ pylori. In conclusion, the lack of association of acute perforated duodenal ulcer and $H$ pylori infection suggests that perforated duodenal ulcer has a different pathogenesis from chronic duodenal ulcer disease, and that the first should not be regarded simply as a complication of the second.

(Gut 1993; 34: 1344-1347)
\end{abstract}

Helicobacter pylori infection of the antral mucosa plays an important part in the pathogenesis of chronic recurrent duodenal ulceration. More than $95 \%$ of such patients have the infection and eradicating it considerably reduces the ulcer recurrence rate. ${ }^{1-3}$ The role of $H$ pylor infection in chronic duodenal ulcer disease may be explained by the fact that it causes excessive release of gastrin by the antral mucosa, which in turn stimulates excessive acid secretion. ${ }^{4}$

Although the role of $H$ pylori in the pathogenesis of chronic duodenal ulcer disease is now well established, its importance in acute perforated duodenal ulcer is unknown. The aim of this study was to assess the prevalence of $H$ pylori infection in patients having a laparotomy for repair of a perforated duodenal ulcer.

\section{Patients and methods}

Over a one year period, patients presenting with a perforated duodenal ulcer were recruited from seven hospitals in the Glasgow area, covering a population of approximately one million. All patients were identified by regular contact with the Emergency Theatre departments of each hospital. The patients were visited during their hospital stay, usually between days 3-5 after operation. The operation notes were examined (by DHR) and only those patients identified as having perforation of a duodenal ulcer were included. Patients with perforation of prepyloric or gastric ulcers were excluded.

After informed consent was obtained, the following details were recorded: age, sex, past medical history, past history of ulcer disease, history of dyspepsia, drug history, smoking and drinking habits, family history, and drugs given during hospital stay. A patient was only considered to have a past history of duodenal ulcer disease if an active ulcer or deformed duodenum had been shown previously by barium meal or endoscopy or at previous laparotomy. A patient was considered to have a history of dyspepsia if they had experienced intermittent upper abdominal pain with some relation to eating. Information was also obtained from the operation notes or speaking to the surgeon who performed the procedure, or both to ascertain whether the perforated ulcer had the appearance of an acute or chronic ulcer.

Within five days of the patients admission for acute perforated duodenal ulcer, $30 \mathrm{ml}$ of venous blood was taken for $H$ pylori serology. This was allowed to clot and then centrifuged and the serum stored at $-20^{\circ} \mathrm{C}$. As a further means of assessing $H$ pylori state, patients were requested to attend for a ${ }^{14} \mathrm{C}$-urea breath test at the Western Infirmary, Glasgow. This was performed at least four weeks after both discharge and withdrawal from any drugs. On that occasion a further blood sample was obtained from these patients for repeat $H$ pylori serology.

For control purposes, serum samples were obtained for $H$ pylori serology from 80 age and sex matched patients admitted to one of the hospitals. This serum was again obtained within two days of admission and those patients suffered from a wide range of medical and surgical conditions.

Studies were also performed to exclude the possibility that laparotomy might interfere with the serology test for $H$ pylori infection. This was 
TABLE I Details of the three patients who had recurrent perforations

\begin{tabular}{|c|c|c|c|c|c|c|}
\hline Sex & Age & $\begin{array}{l}\text { Time interval } \\
\text { between } \\
\text { perforations }\end{array}$ & Drug treatment & Alcohol & Smoker & $\begin{array}{l}\text { H pylori } \\
\text { state }\end{array}$ \\
\hline Male & 39 & 12 years & $\underset{\text { antagonists }}{\text { Regular } \mathrm{H}_{2}}$ & $<10$ units/week & Yes & Positive \\
\hline Female & 61 & 5 years & $\underset{\text { antagonists }}{\text { Intermitent } \mathrm{H}_{2}}$ & None & Yes & Positive \\
\hline Male & 49 & 6 months & $\underset{\text { antagonists }}{\text { Regular } \mathrm{H}_{2}}$ & $>20$ units/week & Yes & Positive \\
\hline
\end{tabular}

done by obtaining serum samples from three patients obtained before and five days after surgery.

\section{ANALYSES}

$H$ pylori serology was performed using a commercial IgG ELISA kit (Helico G serology kit, Porton, Cambridge, UK). This has been validated in our own hospital and with a titre of $18 \mathrm{IU} / \mathrm{ml}$ or less as negative, has a sensitivity of $88 \%$ and specificity of $89 \%$.

The ${ }^{14} \mathrm{C}$-urea breath test was performed as previously described. ${ }^{5}$ This has also been validated in our own unit and using a 20 minute value of $>20$ (percentage ${ }^{14} \mathrm{C}$ dose per $\mathrm{mmol}$ $\mathrm{CO}_{2} \times 100 \times \mathrm{kg}$ body wt) as positive has a sensitivity and specificity of $>95 \%$. The study was approved by the Western Infirmary Ethical Committee.

\section{Results}

One hundred and eleven patients were identified with acute perforated duodenal ulcer during the 12 months of the study. Thirty one of those were unsuitable for entry to the study because of early

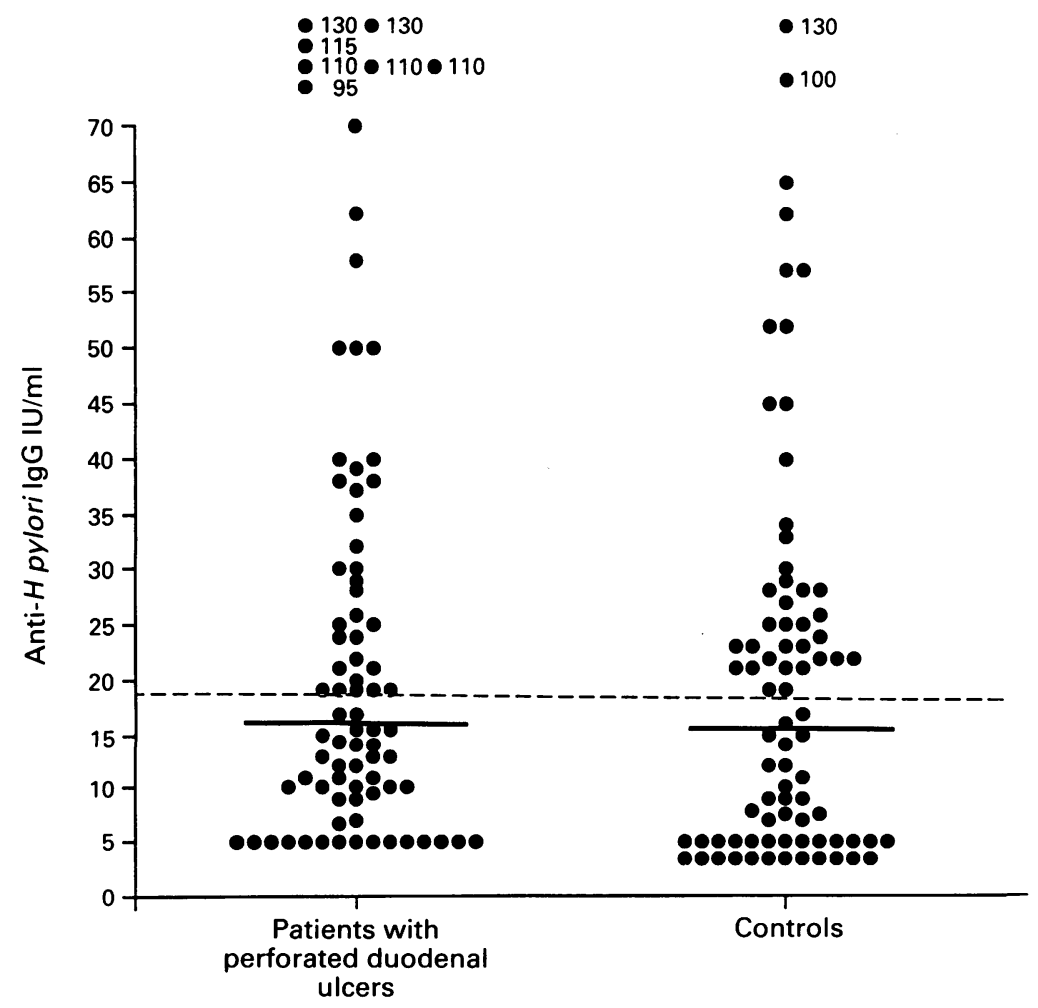

Figure 1: IgG titre to $\mathrm{H}$ pylori in 80 patients presenting with acute perforated duodenal ulcer and in 80 age and sex matched hospital controls. The median values are shown by horizontal lines and the upper limit for negative serology shown by the broken line. postoperative death, refusal to sign a consent form, or inability to sign it on account of mental confusion. Consequently, 80 patients were enrolled into the study. Their mean age was 52 years (range $17-85)$ and $59(74 \%)$ were men. Three (4\%) were taking steroids and $35(44 \%)$ NSAIDs. Sixty seven (84\%) of the patients smoked and $32(40 \%)$ drank more than 15 units of alcohol per week. Twenty one (26\%) had a family history of ulcer disease. Only $19(24 \%)$ had a past history of ulcer disease and only 31 (39\%) had a history of dyspepsia for more than three months. Eighteen (22\%) had been on acid inhibitory treatment at the time of perforation and only a further $10(13 \%)$ had previously had acid inhibitory treatment.

Two of the patients had experienced a previous perforation, which had been treated by simple closure and omental patch. A further patient who presented with his first perforation in this study and was treated with simple closure and omental patch presented with a further perforation of duodenal ulcer six months later. Only his first presentation was included in the analysis. Table I gives further details of these three patients.

In 71 of 80 patients, the surgeon considered the perforation to be acute and in only nine was it considered to be a perforation against a background of chronic duodenal ulceration. All patients except three were treated surgically by simple closure and omental patch. Because of a history of chronic duodenal ulceration, one patient, a 39 year old man, had a vagotomy and pyloroplasty, and one patient, a 55 year old man, a vagotomy and gastroenterostomy. The third, a 75 year old man, had a polya partial gastrectomy because of technical difficulties in oversewing his chronic duodenal ulcer.

Anti-H pylori IgG serology performed in these 80 patients during their admission for acute duodenal ulceration showed that $47 \%$ were positive and $53 \%$ negative (Fig 1). Each of the three patients with recurrent perforation were positive for $H$ pylori. Fifty one patients attended for a ${ }^{14} \mathrm{C}$ urea breath test and by this $49 \%$ were positive and $51 \%$ negative (Fig 2). The patients who attended for the breath test were representative of the entire 80 patients studied, having a mean age of 50 years (range 19-85) and $82 \%$ being men. Only five of these patients who attended for the breath test had received drugs for longer than 24 hours after their perforation and there was no association of perioperative treatment and subsequent breath test result (Table II).

The mean age of the 80 control patients was 46 years (range 19-89) and 73\% were men. Fifty per cent of these control patients had positive IgG serology for $H$ pylori. This rate was not significantly different from the perforated duodenal ulcer patients (Fig 1). The median anti-H pylori IgG titre in the control patients was $15.5 \mathrm{IU} / \mathrm{ml}$, which was not significantly different from that of $16 \mathrm{IU} / \mathrm{ml}$ in the patients with perforated duodenal ulcers.

In the three patients whose anti- $H$ pylor $\mathrm{IgG}$ titre was assessed before and after operation, there was no evidence of any change in the titre induced by operation. The mean titre was 25 


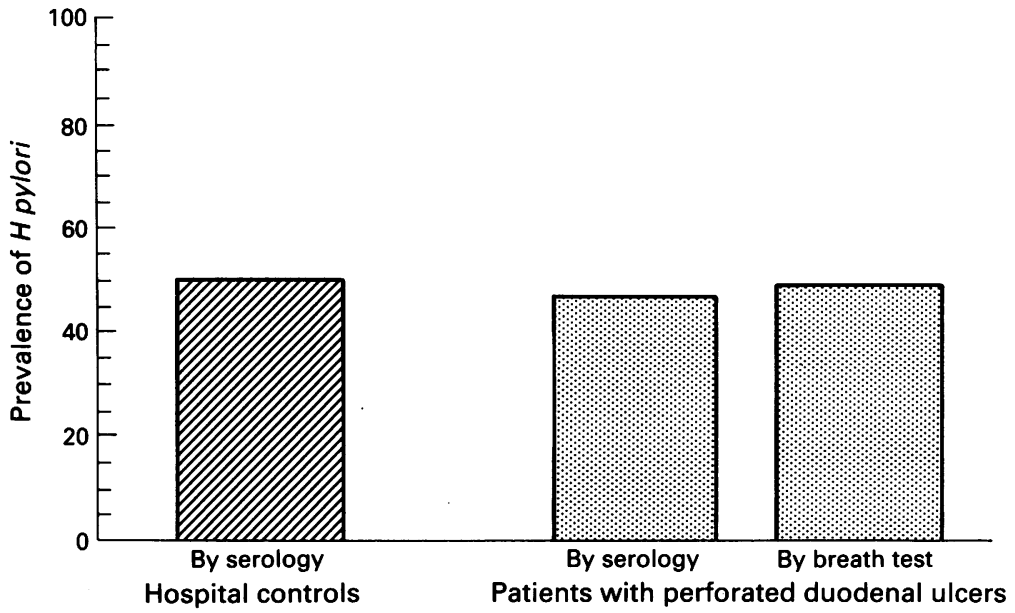

Figure 2: Prevalence of $\mathrm{H}$ pylori in patients presenting with acute perforated duodenal ulcer and in hospital control patients. Eighty patients with perforated duodenal ulcers were examined by serology and 51 also by breath test. Eighty control patients were examined by serology.

(range 22-34) before and 27 (range 13-30) five days after surgery. In the 51 patients who had their serology checked both at the time of acute presentation and again 6-10 weeks later, the proportion who were positive was similar on both occasions being $57 \%$ and $65 \%$, respectively.

A comparison was made of the $H$ pylori positive and negative perforated duodenal ulcer patients as assessed with IgG serology (Table III). This showed that they were similar with respect to age, sex, smoking and drinking habits, past history of ulcer disease, family history, and NSAID use. In the 38 patients presenting with perforated duodenal ulcer while receiving NSAID treatment or steroids, the prevalence of $H$ pylori was only $44 \%$.

\section{Discussion}

This study shows that the prevalence of $H$ pylori infection in patients presenting with acute perforation of a duodenal ulcer is only about $50 \%$ and no higher than that in a control hospital population. This contrasts with the prevalence of $>95 \%$ in the general duodenal ulcer patient population. 6

The possibility that our study has underestimated the prevalence of the infection is unlikely. The serological method of determining the $H$ pylori state has been shown to be reliable in our own unit and in other centres. ${ }^{78}$ The possibility that the laparotomy and anaesthetic might have adversely affected the reliability of the IgG ELISA test was examined and excluded. In addition, assessment of the $H$ pylori state by the ${ }^{14} \mathrm{C}$-urea breath test one month after hospital discharge and withdrawal of all drug treatment provided independent confirmation of the $H$ pylori state. Recent exposure to drugs can produce a negative breath test by suppressing the infection. Careful assessment of drugs used during or after surgery showed, however, that none of the patients had received drug regimens likely to have eradicated $H$ pylori. Our finding that the prevalence of $H$ pylori infection is not increased in patients presenting with perforated duodenal ulcer is consistent with the recent report by Debongnie and Legros. ${ }^{9}$
The previous studies that have shown a high prevalence of $H$ pylori in duodenal ulcer patients and have shown that eradicating the infection reduces the ulcer relapse rate have consisted almost exclusively of patients with chronic recurrent duodenal ulceration. ${ }^{6}$ The patients in this study who presented with perforation represent a different subgroup of duodenal ulcer disease in that only $24 \%$ had a previous history suggestive of duodenal ulceration and only $35 \%$ had ever received treatment with acid inhibitory agents. The appearance of the duodenum at surgery also showed that most of the patients had an acute perforation without evidence of chronic recurrent duodenal ulcer disease. Our patients therefore differed from those in whom $H$ pylori prevalence has been studied previously not only in presenting with a complication of duodenal ulceration but also by presenting with acute rather than chronic duodenal ulcer disease. Though there is convincing evidence that $H$ pylori plays a part in chronic recurrent duodenal ulceration, its role in acute duodenal ulcer disease is not supported by this study.

The possibility that acute perforated duodenal ulceration could be associated with the early phase of $H$ pylori infection before IgG seroconversion has had time to occur must be considered. The fact that the prevalence of the infection, however, was low by the urea breath test as well as by serology and the similar prevalence of seropositivity at acute presentation and repeat testing 6-8 weeks later exclude this possibility.

A recent study from Hong Kong has showed that patients presenting with acute bleeding duodenal ulceraction also have a lower prevalence of $H$ pylori infection (71\%) than

TABLE II Details of drugs given to the 25 patients with a positive ${ }^{14} \mathrm{C}$-urea breath test and 26 patients with negative ${ }^{14} \mathrm{C}$-urea breath test at 4 to 10 weeks after hospital discharge

\begin{tabular}{lcc}
\hline & $\begin{array}{c}\text { H pylori } \\
\text { positive }\end{array}$ & $\begin{array}{c}\text { H pylori } \\
\text { negative }\end{array}$ \\
\hline Nil & 5 & 4 \\
Cefuroxine single dose & 3 & $\mathrm{Nil}$ \\
Cefuroxine for 24 hours & 1 & 2 \\
Cefuroxine for 3 days & $\mathrm{Nil}$ & 1 \\
Cefuroxine+metronidazole single dose & 4 & 11 \\
Cefuroxine+metronidazole for 24 hours & 10 & 3 \\
Cefuroxine+metronidazole for 3 days & $\mathrm{Nil}$ & 1 \\
Cefuroxine+metronidazole +amoxycillin & 1 & 2 \\
$\quad$ for 3-5 days & $\mathrm{Nil}$ & 1 \\
$\begin{array}{l}\text { Metronidazole single dose } \\
\text { forillin+gentamicin+metronidazole }\end{array}$ & 1 & 1 \\
& & \\
\hline
\end{tabular}

TABLE III Comparison of the patients with perforated duodenal ulcers found to be positive and negative for $\mathrm{H}$ pylori by IgG serology

\begin{tabular}{lll}
\hline & $\begin{array}{l}\text { H pylori } \\
\text { positive }\end{array}$ & $\begin{array}{l}\text { H pylori } \\
\text { negative }\end{array}$ \\
\hline Mean age (y) & 51 & 53 \\
Range (y) & $17-85$ & $21-85$ \\
Male & $74 \%(32)$ & $71 \%(27)$ \\
Smoking & $83 \%(35)$ & $84 \%(32)$ \\
Alcohol >15 units/week & $38 \%(16)$ & $42 \%(16)$ \\
Past history of duodenal ulcer & $24 \%(10)$ & $24 \%(9)$ \\
Family history of duodenal ulcer & $29 \%(12)$ & $24 \%(9)$ \\
Current steroids & $5 \%(2)$ & $3 \%(1)$ \\
Current NSAID treatment & $45 \%(19)$ & $44 \%(16)$ \\
Dyspepsia > 3/12 & $34 \%(14)$ & $45 \%(17)$ \\
Current acid inhibitory drugs & $14 \%(6)$ & $32 \%(12)$ \\
Previous acid inhibitory drugs & $12 \%(5)$ & $14 \%(5)$ \\
\hline
\end{tabular}


those presenting with recurrent pain (93\%) $(\mathrm{p}<0.012) .{ }^{10}$ In that study 19 patients in the bleeding group were taking NSAIDs but there was no correlation of NSAIDs use with $H$ pylori state.

The fact that there is no increased prevalence of $H$ pylori infection in patients presenting with perforated duodenal ulcer shows that this form of ulcer disease has a different pathogenesis from chronic recurrent duodenal ulcer disease. It also suggests that other pathogenic factors must participate in perforated duodenal ulcer disease. Half of our perforated duodenal ulcer patients were regularly taking NSAIDs or systemic steroids. This is consistent with previous studies of perforated duodenal ulcer, which have shown a prevalence of NSAID use ranging from $32-82 \% .^{11-13}$ In the study by Armstrong et al the prevalence of NSAID use in the perforated duodenal ulcer patients was $60 \%$ compared with only $9.9 \%$ in the hospital control group. ${ }^{11}$ Smoking is another important risk factor for duodenal ulceration ${ }^{14}$ and it is of note that the most of our perforated duodenal ulcer patients $(84 \%)$ were smokers.

The fact that the prevalence of $H$ pylori in the 35 patients presenting with perforated duodenal ulcer while taking NSAIDs was similar to the hospital control population shows that the infection does not influence the likelihood of this complication occurring as a result of such treatment. Several studies including one from our own group have shown that the commonest cause of duodenal ulceration occurring in patients without $H$ pylori is NSAID use $\mathrm{s}^{15-17}$ showing that the ulcerogenic effect of these agents is not dependent upon underlying $H$ pylori infection.

The finding of this study also raises the question of the relation between chronic recurrent duodenal ulcer disease and ulcer perforation. Our results show that most patients presenting with perforated duodenal ulcer have no evidence of underlying chronic duodenal ulcer disease. Only $25 \%$ had evidence of chronic duodenal ulcer disease and this subgroup included the three patients with recurrent perforations.

In conclusion, this study shows that by contrast with chronic recurrent duodenal ulceration, there is no association between $H$ pylori infection and acute perforated duodenal ulcer. This suggests that acute perforated duodenal ulcer has a different pathogenesis from chronic recurrent duodenal ulcer disease and that the first should not be regarded as simply a complication of the second.

The authors wish to acknowledge the co-operation of the consultant surgeons in the Glasgow area who allowed their patients to be studied. We also acknowledge the secretarial assistance of Mrs Dorothy Ronney and the staff of the Department of Clinical Physics who performed the breath tests. This study was supported by a grant from the Biomedical and Clinical Research Committee of the Scottish Home and Health Department.

This work was presented at the 1992 Spring Meeting of the British Society of Gastroenterology and appeared as an abstract in Gut.

1 Coghlan JG, Gilligan D, Humphries H, McKenna D, Dooley C, Sweeney E, et al. Campylobacter pylori and recurrence of duodenal ulcers. A 12 month follow-up study. Lancet 1987; ii: $1109-11$.

2 Marshall BJ, Goodwin CS, Warren JR, Murray R, Blincow ED, Blackbourn SJ, et al. Prospective double-blind trial of duodenal ulcer relapse after eradication of campylobacter duodenal ulcer relapse after eradi.

3 Rauws EAJ, Tytgat GNJ. Cure of duodenal ulcer associated with eradication of Helicobacter pylori. Lancet 1990; 335: with e. $233-5$.

4 El-Omar E, Penman I, Dorrian CA, Ardill JES, McColl KEL. Eradicating Helicobacter pylori infection lowers gastrinmediated acid secretion by two-thirds in duodenal ulcer patients. Gut 1993; 34: 1060-5.

5 Neithercut WD, Milne A, Chittajallu RS, Nujumi AMEl, McColl KEL. Detection of Helicobacter pylori infection of the gastric mucosa by measurement of gastric aspirate ammonium and urea concentrations. Gut 1991; 32: 973-6.

6 Wyatt JI. Helicobacter pylori, duodenitis and duodenal ulceration in Helicobacter pylori and gastroduodenal disease. Eds Rathbone BJ, Heatley RV. 2nd edition. London: Blackwell Scientific, 1992;140-50.

7 Logan RPH, Polson RJ, Misiewicz JJ, Rao G, Karim NQ, Newell D, et al. Simplified single sample ${ }^{13}$ carbon urea breath test for Helicobacter pylori: Comparison with histology, culture, and ELISA serology. Gut 1991; 32: histology,

8 Mendall MA, Goggin P, Bellhouse A, Molineaux NJ, Marrero $\mathrm{J}$, Tucker RJ, et al. Performance of a commercially available serological test for Helicobacter pylori and its relation to age. Gut 1991; 32: A1257.

9 Debongnie JC, Legros G. Gastric perforation: An acute disease unrelated to $\mathrm{H}$ pylori? Rev Esp Enferm Dig 1990; 78 (suppl 1): 71-2.

10 Hosking SW, Yung MY, Chung SC, Li AKC. Differing prevalence of Helicobacter in bleeding and non-bleeding ulcers. Gastroenterology 1992; 102: A85.

11 Armstrong CP, Blower AL. Non-steroidal anti-inflammatory drugs and life threatening complications of peptic drugs and life threatening com

12 Horowitz J, Kukora JS, Ritchie WP. All perforated ulcers are not alike. Ann Surg 1989; 209: 693-7.

13 Collier DStJ, Pain JA. Non-steroidal anti-inflammatory drugs and peptic ulcer perforation. Gut 1985; 26: 359-63.

14 Korman MG, Hansky J, Eaves ER, Schmidt GT. Influence of cigarette smoking on healing and relapse in duodenal ulcer disease. Gastroenterology 1983; 85: 871-4.

15 Borody TJ, George LL, Brandl S, Andrews P, Ostapowicz N, Hyland $\mathrm{L}$, et al. Helicobacter pylori-negative duodenal ulcer. Am $\mathcal{f}$ Gastroenterology 1991; 86: 1154-7.

16 Nensey YM, Schubert TT, Bologna SD, Ma CK. Helicobacter pylori-negative duodenal ulcer. Am F Med 1991; 91: 15-8.

17 McColl KEL, El-Nujumi AM, Chittajallu RS, Dahill SW, Dorrian CA, Graham H, et al. A study of the pathogenesis of Helicobacter pylori-negative chronic duodenal ulcer disease. Gut 1993; 34: 762-9. 